University of Warwick institutional repository: http://go.warwick.ac.uk/wrap

This paper is made available online in accordance with

publisher policies. Please scroll down to view the document itself. Please refer to the repository record for this item and our policy information available from the repository home page for further information.

To see the final version of this paper please visit the publisher's website. Access to the published version may require a subscription.

Author(s): Elvira Bramona, , Madiha Shaikha, Matthew Broomea, Julia Lappina, Daniel Bergéb, Fern Daya, James Woolleya, Paul Tabrahama, Mercè Madrec, Louise Johnsa, Oliver Howesa, Lucia Valmaggiaa, Víctor Pérezc, Pak Shamd, Robin M. Murraya and Philip McGuirea Article Title: Abnormal P300 in people with high risk of developing psychosis.

Year of publication: 2008

Link to published version:

http://dx.doi.org/doi:10.1016/j.neuroimage.2007.12.038

Publisher statement: N/A 
Elsevier Editorial System(tm) for Neurolmage

Manuscript Draft

Manuscript Number: NIMG-07-745R1

Title: Abnormal P300 in people with high risk of developing psychosis

Article Type: Regular Article

Section/Category: Systems Neuroscience

Keywords:

Corresponding Author: dr Elvira Bramon, M.D., Ph.D.

Corresponding Author's Institution: Institute of Psychiatry, London, UK.

First Author: elvira Bramon, M.D., PhD

Order of Authors: elvira Bramon, M.D., PhD; Madiha Shaikh, BSc Psychology; Matthew Broome, BSc, MBChB, MRCPsych; Julia Lappin, MBBS, MRCPsych; Daniel Berge, MD; Fern Day, BSc; James Woolley, BSc, MBBS, MRCP, MRCPsych; Paul Tabraham, BSc, DClinPsy; Merce Madre, MD; Louise Johns, MA, DPhil, DClinPsy; Lucia Valmaggia, MSc, PhD; Victor Perez, MD, PhD; Pak Sham, MBBS, MRCPsych, PhD; Robin Murray, MD, DSc; Philip McGuire, MBBS, MRCPsych, MD, PhD

Manuscript Region of Origin:

Abstract: Background: Individuals with an "At Risk Mental State" (or "prodromal" symptoms) have a 20-40\% chance of developing psychosis; however it is difficult to predict which of them will become ill on the basis of their clinical symptoms alone. We examined whether neurophysiological markers could help to identify those who are particularly vulnerable.

Method: 35 cases meeting PACE criteria for the At Risk Mental State (ARMS) and 57 controls performed an auditory oddball task whilst their electroencephalogram was recorded. The latency and amplitude of the P300 and N100 waves were compared between groups using linear regression. 
Results: The P300 amplitude was significantly reduced in the ARMS group [8.6 \pm 6.4 microvolt] compared to controls [12.7 \pm 5.8 microvolt] $(p<0.01)$. There were no group differences in P300 latency or in the amplitude and latency of the N100. Of the at-risk subjects that were followed up, seven (21\%) developed psychosis. Conclusion: Reduction in the amplitude of the P300 is associated with an increased vulnerability to psychosis. Neurophysiological and other biological markers may be of use to predict clinical outcomes in populations at high risk. 
Dr. Elvira Bramon Institute of Psychiatry, KCL

(PO Box 63)

De Crespigny Park

London SE5 8AF

United Kingdom

Tel: +44 (0) 2078485036

Email: elivra.bramon@iop.kcl.ac.uk

$27^{\text {th }}$ November 2007

Dear editor

\section{Revised manuscript NIMG-07-745}

Please find attached a fully revised manuscript titled "Abnormal P300 in people with high risk of developing psychosis". We also enclose a letter with the comments from the reviewers and our detailed answers on how we have done all the changes requested.

My coauthors and I would be grateful if you could consider this new version for publishing in Neuroimage.

Your Sincerely

Elvira Bramon MD, $\mathrm{PhD}$

Corresponding author 


\section{* 2. Response to Reviews}

RESPONSE TO REVIEWS - MS. No.: NIMG-07-745

Title: Abnormal P300 in people with high risk of developing psychosis Corresponding Author: dr Elvira Bramon

Authors: Madiha Shaikh, BSc Psychology; Matthew Broome, BSc, MBChB, MRCPsych; Julia Lappin, MBBS, MRCPsych; Daniel Berge, MD; Fern Day, BSc; James Woolley, BSc, MBBS, MRCP, MRCPsych; Paul Tabraham, BSc, DClinPsy; Merce Madre, MD; Louise Johns, MA, DPhil, DClinPsy; Lucia Valmaggia, MSc, PhD; Victor Perez, MD, PhD; Pak Sham, MBBS, MRCPsych, PhD; Robin Murray, MD, DSc; Philip McGuire, MBBS, MRCPsych, MD, PhD

\section{RESPONSE TO REVIEWER \#1:}

Thank you for your comments, which have improved the paper and are very encouraging for us. Below are your suggestions in blue italic and how we have amended the manuscript accordingly in black.

This study investigated the differences in P300 between at-risk individuals for psychosis and a matched control group. Reduced P300 amplitude was found associated with at risk state, independent of other demographic variables. The manuscript is well written, is based on standard ERP techniques and the results are clearly presented.

As a minor suggestion, I would request the authors include the criteria of Yung et al. as the journal is not widely available.

These criteria have now been briefly mentioned in the paper. See $1^{\text {st }}$ paragraph of methods section page 4.

Please state if those individuals who progressed to psychosis during follow-up did differ from the others in demographic and ERP variables. Even though preliminary at this stage, this would be of considerable interest!

Compared to the rest of cases at risk, the seven individuals who went on to develop psychosis did not differ significantly in sex or ethnicity (Pearson chi-square $p=0.49$ and $p=0.76$ respectively) or age ( $t$-test; $p=0.93$ ). Those making a transition to psychosis were marginally more educated but this was only at trend level with a 3 year average difference in the age at which they completed their studies (t-test; $p=0.07$ ).

Similarly, logistic regression analyses showed that compared to those who remained at risk, the seven cases who made a transition to psychosis had no significant differences in P300 amplitude/latency or N100 amplitude/latency ( $p$ values ranging from 0.30 to 0.63 for all four analyses). We have reported these comparisons very concisely and cautiously because referee \#2 said that these analyses with only 7 individual making a transition were preliminary and power is limited. Please see results section paragraph 2.

\section{RESPONSE TO REVIEWER \#2:}

Thank you for your suggestions, which have improved the paper. Below are your comments in blue-italics and how we have amended the manuscript accordingly in black with cross-references to the revised manuscript.

This paper addresses an important and timely topic, namely, whether auditory P300 is reduced in subjects with at risk mental states and whether the P300 predicts subsequent conversion to psychosis. The study finds a significant deficit in P300 in ARMS subjects, relative to controls, replicating a previously a previously published report. The study had the potential to incrementally 
contribute to the literature by examining the utility of baseline P300 deficits as a predictor of subsequent conversion to psychosis; however, the negative finding coupled with the lack of power for this analysis (only 7 converters) make this aspect of the study inconclusive. More detailed comments are provided below:

We have added a paragraph in the discussion to acknowledge the limitation of our small group of converters and how we have low statistical power to compare them against those remaining at risk. This is also mentioned in the conclusion.

Please note that referee \#1 requested we do undertake a preliminary comparison of converters versus non-converters in demographics as well as P300 and N100. We reported this in the results section very concisely (paragraph 2); although we acknowledge this is inconclusive (discussion paragraph 6 dealing with study limitations).

1. The introduction fails to distinguish P300 elicited by task-relevant target stimuli, sometimes referred to as "P3b", from P300 elicited by task-irrelevant infrequent novel or salient stimuli, sometimes referred to as "P3a". The current study only examines the auditory target P3b, a subset of possible P300 measures that one might choose to study in At-Risk Mental State subjects. It is important to make these distinctions in order for readers unacquainted with the P300 literature to understand the nature of this ERP component and the limits of the generalizability of the current study.

We have now made the distinction between the two P300 sub-components and their nature very clear both in the introduction (paragraph 1 and briefly in paragraph 2) and also in the discussion (paragraph 4).

2. This study lacks a schizophrenia comparison group, making it difficult to place the deficit observed in the ARMS group into perspective within the illness course of schizophrenia. In other words, the current study design does not allow any statements about whether the P300 deficits observed are similar or attenuated relative to schizophrenia patients at their first episode of illness. This design limitation does not invalidate the results, but it does limit the ability to make inferences regarding P300 as trait marker of illness vulnerability versus a pathophysiological marker of illness progression during transition to psychosis. This limitation should be mentioned in the discussion.

We acknowledge this limitation in our study. A direct comparison of controls, high-risk and first episode patients would have been ideal. We included an additional paragraph in the discussion to report this and other limitations (paragraph 6 in discussion).

We published a meta-analysis of patients with schizophrenia (Bramon et al., 2004b) and of unaffected relatives (Bramon et al., 2005). These were the pooled standardized effect sizes (PSES) obtained:

PSES patients $v$ controls: $0.85(95 \% \mathrm{Cl}: 0.65$ to $1.05 ; p<0.001)$

PSES relatives $v$ controls: $0.61(95 \% \mathrm{Cl}: 0.30$ to $0.91 ; p<0.001)$.

PSES calculated above as Cohen's d (Cohen, 1969) allow a direct comparison of the strength of an effect. In this present study the standardized difference between at-risk subjects and controls at centro-parietal sites (averaging CZ and PZ measures as in the meta-analysis) is 0.49 . This would indicate that the deficits found in cases at-risk due to prodromal symptoms are less severe than those reported for chronic patients but fall within the confidence interval of the deficits described in 
populations with genetic risk, such as the unaffected first degree relatives of patients. We thought it would improve the paper to mention this briefly in the discussion.

3. The EEG/ERP methods are inadequately described. Although we are told that the data were epoched and baseline corrected, we are not told the length of the epochs nor the length of the baseline period subtracted from the epochs. The authors mention that they applied the Neuroscan's ocular correction algorithm, but they do not mention whether epochs were rejected when they contained a voltage value exceeding some criterion (a step that is commonly referred to as "artifact rejection"). Were the EEG epoch data subject to artifact rejection? If so, this should be explicitly described.

We intended to write a brief report and refer readers to our previous papers for further details. However, as requested, we have now amended the manuscript to have a complete EEG methodology section.

Neuroscan have an artifact rejection procedure where epochs containing a voltage value above a chosen value are automatically excluded; however this can lead to substantial data loss. Also, if a group systematically blinks more (as may happen in patients on antipsychotic and other medication) this could lead to bias. We therefore use another ocular artifact rejection procedure, also available in Neuroscan, where the effect of blinks is minimized by linear regression methods and all epochs collected can be used. A template of blinks is obtained for each individual (and each experiment they did) and this is used to obtain coefficients and apply corrections to all other channels. This is a well-known procedure developed by Semlitsch (Semlitsch et al., 1986) and that we have used in several of our previous papers successfully (Bramon et al., 2004a; Bramon et al., 2006; Bramon et al., 2005; Hall et al., 2007a; Hall et al., 2007b; Hall et al., 2006a; Hall et al., 2006b; Hall et al., 2004; Schulze et al., In press).

4. The authors state that the EEG signal was digitized at $500 \mathrm{~Hz}$ with a bandpass filter of .05 to $200 \mathrm{~Hz}$. Although the Nyquist rule stipulates that signals need to be sampled at least twice as fast as the highest frequency of interest in order to avoid aliasing. Neuroscan Synamps amplifiers usually implement a more stringent rule, requiring a sampling rate of 4 times the highest frequency of interest as defined by the low pass filter setting. Did the authors use Neuroscan amplifiers? If so, they should confirm that they were able to digitize the EEG signal at $500 \mathrm{~Hz}$ with a $200 \mathrm{~Hz}$ low pass filter setting. At least using older Synamps amplifliers, this would not have been possible.

Many thanks for spotting this. The sampling rate used in this sample was $1000 \mathrm{~Hz}$. This is now corrected in the methods. We used a Neuroscan Synamps amplifier purchased in 2003 and as you suggest this uses a more stringent Nyquist rule.

5. It is not clear why the authors only examined the N100 to the standard stimulus. The N1 to standards can be rather attenuated due to the lack of sufficient time between auditory stimulus presentations to allow full recovery of the N100 neural generators. The N100 to the target stimuli do not suffer from this recovery constraint because they are well separated in time. Moreover, N100 can be augmented by attention, further motivating an analysis of the N100 elicited by the auditory target stimuli. Addition of this analysis would strengthen the paper.

We reported the N100 to standard stimuli because with 320 of them we get a better signal to noise ratio. We have now added the analyses of N100 response to rare tones (see results section) and we have amended the methods section accordingly. As for the frequent tones, there were no significant differences in N100 to the rare tones between cases at risk and controls. Thus the main findings of the paper remain the same. Because we have had to go back to the original waveforms 
and do further signal processing and statistical analyses it has taken us some time to get back with the amended manuscript.

6. An exclusion criterion for the healthy controls, but not the at risk patients, was alcohol or drug abuse or dependence in the past 12 months. This introduced a confound in the group comparison, since the at risk subjects used illicit drugs significantly more than the healthy controls. How can the authors be sure that the group differences they observed are due to the at-risk mental state rather than their increased rate of drug use? Moreover, inclusion of drug use history as a covariate in the model is problematic when the groups differ on the covariate (See Miller and Chapman, 2001, "Misunderstanding analysis of covariance", J of Abnormal Psychology). A better strategy would have been to match the groups on drug use.

The exclusion criteria were misreported in the original manuscript and we have amended the methods section to fully clarify that: (i) A DSM-IV diagnosis of alcohol or drug abuse or dependence was an exclusion criterion for all participants and while the patients were referred to a specialist addictions service controls were simply screened out. (ii) However, recreational substance use (alcohol or illicit drugs) not reaching DSM-IV criteria for dependence/abuse were not an exclusion criteria and that's again for all participants. The reason for this was to avoid recruiting a sample of "super-healthy" participants that could not be generalized to the population we are studying (young inner-city London dwellers where recreational drug usage is very prevalent). Despite using the same inclusion/exclusion criteria in the end our groups were not well matched for recreational drug usage and the cases were significantly more likely to report having recreational use than the controls. It is also important to remember that drug usage for this study relied only on self-report and this has important limitations (compared to urine drug screening). In addition, drug usage could well be regarded as a mediating factor rather than a confounder. In any case, we accept this criticism and, since our data collection is ongoing, we will endeavor to improve the group matching for drug use in future.

As you requested and based on Miller and Chapman 2001, we have re-analysed the study without including the drug effect variables and the paper is now amended to report these final statistics. The findings of the paper have not changed. We have also addressed the issue of drugs in the discussion. Finally, we'd like to highlight that confound from prescribed medication is a much more serious problem in this type of case control research and our sample was un-medicated and mostly naïve to psychotropics.

Due to the lack of matching in recreational drug usage, we have run additional analyses examining a group $X$ drug use interaction as well as a main effect of drugs in all the paradigms studied and no significant interaction or main effects were found. The estimated differences varied slightly but the findings of the study were unchanged (there still was a significant effect of group (case/control) on P300 amplitude but not on P300 latency, N100 amplitude or N100 latency). All of this indicates that the findings in this study (most of them negative actually) are not confounded by recreational drug usage. Please see all the analyses in an appendix at the end of this letter.

7. In light of the fact that data were collected from a 64 channel scalp montage, it was disappointing that only midline electrodes Fz, Cz, and Pz were analyzed. Moreover, the analysis approach was rather unconventional, apparently treating these three electrodes as a vector of correlated dependent measures. It is more common, and probably more useful, to include electrodes from sites across the scalp in the analysis, and to explicitly include scalp topography factors in the analysis model. This would allow the authors to examine whether the groups showed differences in the scalp topographies of their P300 (or N100) amplitudes and/or latencies. 
This is particularly important because a number of prior studies have suggested that P300 shows a left-lateralized deficit over temporal scalp sites in schizophrenia patients, a finding that has been linked to MRI volume deficits of the left superior temporal gyrus in these patients.

As requested we have now examined temporal channels for the P300 wave. We have added a paragraph in the results section to report topographic changes both in P300 and N100 in our study (last paragraph) and in the discussion we also address the issue of lateralization of the P300 deficits ( $3^{\text {rd }}$ paragraph).

Most of the P300/N100 literature treats FZ, CZ and PZ as independent measures and report at these three locations only. Our statistics colleagues advised analyzing the data in one model, where we take into account that neighboring electrode measures are not really independent but rather have strong correlations (with coefficients between 0.7 and 0.9 ). We have published similar analyses already in Bramon et al, 2005; Bramon et al, 2006; Schulze et al, 2007.

We agree that the analysis you suggest using electrodes across the scalp including full head topography factors is ideal. However, having collected 64 channels it is extremely complex to execute and to interpret. Other referees may have criticized us given that our sample is of modest size (almost as many electrodes as participants). Thus, given the size of our prodromal sample, we have focused on midline and temporal areas in this paper. We are working to develop the type of analysis you suggest and hope to apply it to our larger datasets.

8. Age was apparently used a covariate in their statistical mode of P300 and N100 effects. It is not clear whether age $x$ group interactions were included or ruled out in their analysis model. The question is whether age relationships with P300 amplitude or latency showed different slopes in the two subject groups, and whether homogeneity of slopes was an implicit assumption of their model. This needs to be clarified.

All our analyses looking at the effect of group on ERPs were adjusted by age as a covariate. This is because several studies and in particular a meta-analysis have found that there is an effect of ageing on P300 especially on its latency which tends to increase in older ages (Polich, 1996). We thought it would be reasonable to adjust our N100 by age too.

We also examined group $x$ age interactions systematically, which were not significant for any of the paradigms examined. In addition the age range of our sample is very narrow (16-35 years) and the two groups did not have significant age differences.

We have amended the final methods section to clarify how we looked at covariates and at interactions. We've also amended the last paragraph of the results section so that this issue of the demographic comparisons is clearer.

9. We are told in the results that there were no significant performance differences between the groups in the oddball task. This conclusion is limited to the accuracy data. Were there reaction time differences between the groups?

The data on reaction time has now been added. Independent sample t-tests indicate that, compared to controls, people at risk for psychosis had similar reaction times. These findings have been briefly added to the results (end of $1^{\text {st }}$ paragraph) and the discussion ( ${ }^{\text {th }}$ paragraph). This has required going back to our original files and has taken some time for processing. 
12. In the results, the authors state: "We found a significant effect of group on $P 300$ amplitude, with lower amplitudes in cases at risk than in controls (Coef. $=-3.4$ microvolt; $95 \% \mathrm{Cl}$ : -5.7 to -1.1 ; p<0.01)." What is this coefficient? How is it interpreted? Is this the predicted or estimated group effect?

Please note your comments jump from point 9 to 12 . We have not received anything else from the journal. The interpretation of this linear regression un-standardized coefficient is that as you move from controls to at risk cases there is a reduction (negative coefficient) of 3.4 microvolt. This is an estimated effect with a $95 \% \mathrm{Cl}-5.7$ to -1.1 , which is significant. We have amended the results section so that this is clearer and rather than using the term "coefficient" we now call this "Estimated difference". Please note that as we have re-analyzed the whole study to drop the effects of illegal drugs the coefficients for group differences have changed slightly (although the findings of the paper remain unaltered).

\section{REFERENCES}

Bramon, E., Croft, R.J., McDonald, C., Virdi, G.K., Gruzelier, J.G., Baldeweg, T., Sham, P.C., Frangou, S., Murray, R.M., 2004a. Mismatch negativity in schizophrenia: a family study. Schizophr Res 67, 1-10.

Bramon, E., Dempster, E., Frangou, S., McDonald, C., Schoenberg, P., MacCabe, J.H., Walshe, M., Sham, P., Collier, D., Murray, R.M., 2006. Is there an association between the COMT gene and P300 endophenotypes? European Psychiatry 21, 70-73.

Bramon, E., McDonald, C., Croft, R.J., Landau, S., Filbey, F., Gruzelier, J.H., Sham, P.C., Frangou, S., Murray, R.M., 2005. Is the P300 wave an endophenotype for schizophrenia? A metaanalysis and a family study. Neuroimage $27,960-968$.

Bramon, E., Rabe-Hesketh, S., Sham, P., Murray, R.M., Frangou, S., 2004b. Meta-analysis of the P300 and P50 waveforms in schizophrenia. Schizophr Res 70, 315-329.

Cohen, J., 1969. Statistical Power Analysis for the Behavioral Sciences, first ed. Academic Press, Inc., New York.

Hall, M.-H., Rijsdijk, F., Picchioni, M., Schulze, K., Ettinger, U., Toulopoulou, T., Bramon, E., Murray, R.M., Sham, P., 2007a. Substantial Shared Genetic Influences on Schizophrenia and Event-Related Potentials. Am J Psychiatry 164, 804-812.

Hall, M.H., Rijsdijk, F., Kalidindi, S., Schulze, K., Kravariti, E., Kane, F., Sham, P., Bramon, E., Murray, R.M., 2007b. Genetic overlap between bipolar illness and event-related potentials. Psychol Med, 1-12.

Hall, M.H., Schulze, K., Bramon, E., Murray, R.M., Sham, P., Rijsdijk, F., 2006a. Genetic overlap between P300, P50, and duration mismatch negativity. Am J Med Genet B Neuropsychiatr Genet 141, 336-343.

Hall, M.H., Schulze, K., Rijsdijk, F., Picchioni, M., Ettinger, U., Bramon, E., Freedman, R., Murray, R.M., Sham, P., 2006b. Heritability and Reliability of P300, P50 and Duration Mismatch Negativity. Behav Genet 36, 845-857. 
Hall, M.H., Schulze, K., Sham, P., Picchioni, M., Ettinger, U., Rijsdijk, F., Bramon, E., Freedman, R., Murray, R.M., 2004. Test-retest reliability of ERP components of P300, P50 and duration mismatch negativity in monozygotic twins. Schizophr Res 67, 129-129.

Schulze, K., Hall, M., Mc Donald, C., Marshall, N., Walshe, M., Murray, R., Bramon, E., In press. Auditory P300 in patients with bipolar disorder and their unaffected relatives. Bipolar Disorders.

Semlitsch, H.V., Anderer, P., Schuster, P., Presslich, O., 1986. A Solution for Reliable and Valid Reduction of Ocular Artifacts, Applied to the P300 Erp. Psychophysiology 23, 695-703.

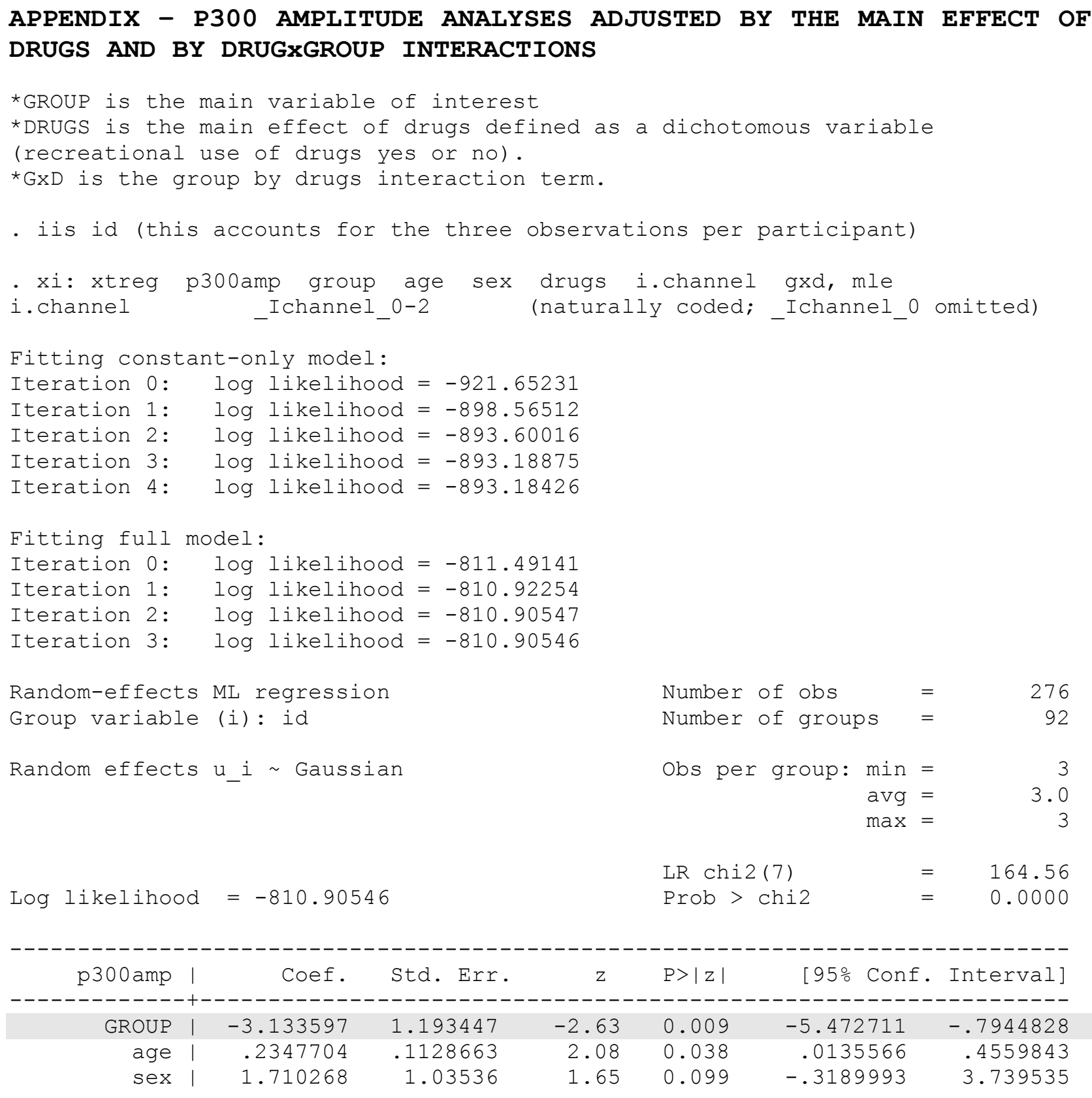

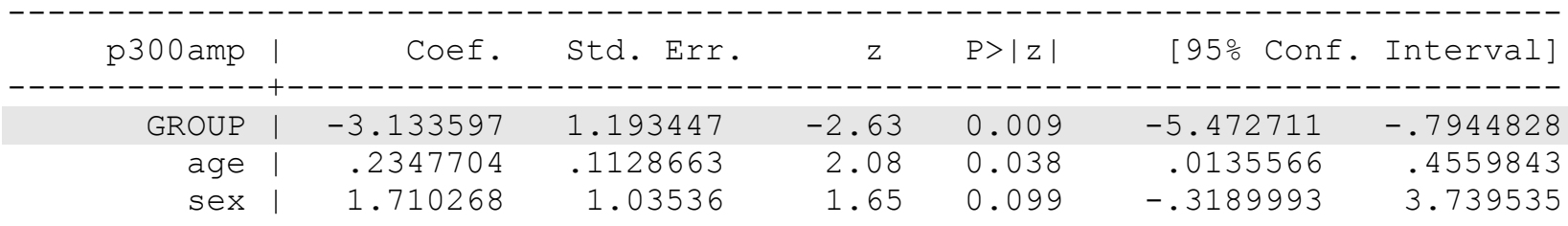




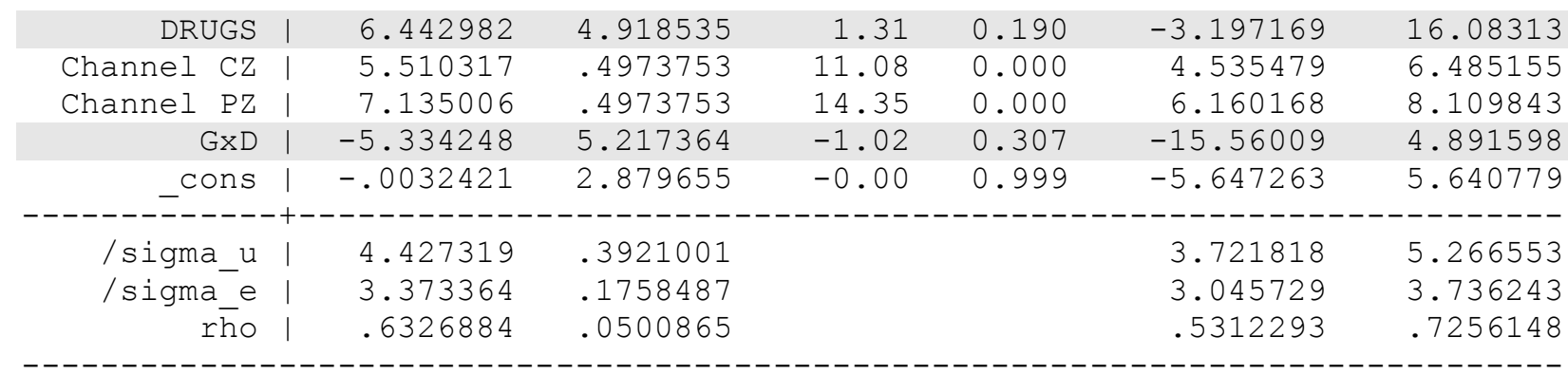

Likelihood-ratio test of sigma_u=0: chibar2 $(01)=109.05$ Prob $>=$ chibar2 $=0.000$

\section{Dropping the GxD interaction term as well as the main effect of DRUGS as these are not significant and as advised by referee we are left with the findings reported in the paper}

. iss id

- xi: xtreg p300amp group age sex i.channel, mle

i.channel _ Ichannel_0-2 (naturally coded; _ Ichannel_0 omitted)

Fitting constant-only model:

Iteration 0: $\quad \log$ likelihood $=-923.94638$

Iteration 1: $\log$ likelihood $=-899.27156$

Iteration 2: $\log$ likelihood $=-893.69728$

Iteration 3: $\log$ likelihood $=-893.19091$

Iteration 4: $\log$ likelihood $=-893.18426$

Fitting full model:

Iteration 0: $\quad \log$ likelihood $=-812.29373$

Iteration 1: $\log$ likelihood $=-811.95089$

Iteration 2: $\log$ likelihood $=-811.94539$

Random-effects ML regression

Group variable (i) : id

Number of obs $=276$

Random effects u_i Gaussian

Number of groups $=92$

Obs per group: $\min =3$

$\operatorname{avg}=\quad 3.0$

$\max =3$

Log likelihood $=-811.94539$

LR $\operatorname{chi2(5)}$

$=162.48$

Prob $>$ chi2 $=0.0000$

\begin{tabular}{|c|c|c|c|c|c|c|}
\hline p300amp | & Coef. & Std. Err. & z & $\mathrm{P}>|\mathrm{z}|$ & [95응 Conf. & Interval] \\
\hline \multicolumn{7}{|c|}{ 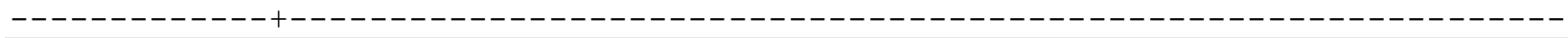 } \\
\hline GROUP | & -2.932581 & 1.066861 & -2.75 & 0.006 & -5.02359 & -.841573 \\
\hline age | & .2406552 & .1140261 & 2.11 & 0.035 & .0171682 & .4641422 \\
\hline sex | & 1.519467 & 1.038355 & 1.46 & 0.143 & -.5156714 & 3.554605 \\
\hline Channel CZ | & 5.510317 & .4973388 & 11.08 & 0.000 & 4.535551 & 6.485083 \\
\hline Channel PZ | & 7.135006 & .4973388 & 14.35 & 0.000 & 6.160239 & 8.109772 \\
\hline _cons | & .0759236 & 2.908449 & 0.03 & 0.979 & -5.624532 & 5.776379 \\
\hline & --- & ------ & & & -- & -------- \\
\hline /sigma_u | & 4.487321 & .3955848 & & & 5275 & 5.333666 \\
\hline /sigma_e | & 3.373364 & .1758164 & & & 3.045786 & 3.736173 \\
\hline$r \bar{h} \circ$ | & .6389226 & .0495039 & & & .5384387 & .7306103 \\
\hline
\end{tabular}


Likelihood-ratio test of sigma $u=0$ : chibar2(01) $=111.70$ Prob $>=$ chibar2 $=0.000$ 


\section{Abnormal P300 in people with high risk of developing psychosis}

Elvira Bramon ${ }^{1} \mathrm{MD}, \mathrm{PhD}$, Madiha Shaikh ${ }^{1} \mathrm{BSc}$, Matthew Broome ${ }^{1} \mathrm{BSc}, \mathrm{MBChB}, \mathrm{MRCPsych}$, Julia Lappin $^{1}$ MBBS, MRCPsych, Daniel Bergé ${ }^{2}$ MD, Fern Day ${ }^{1}$ BSc, James Woolley ${ }^{1}$ BSc, MBBS, MRCP, MRCPsych, Paul Tabraham ${ }^{1}$ BSc, DClinPsy, Mercè Madre ${ }^{3}$, MD, Louise Johns ${ }^{1}$ MA, DPhil, DClinPsy, Lucia Valmaggia ${ }^{1}$ MSc, PhD, Víctor Pérez ${ }^{3}$ MD, PhD, Pak Sham ${ }^{4}$ MBBS, MRCPsych, PhD, Robin M. Murray ${ }^{1}$ MD, DSc, Philip McGuire ${ }^{1}$ MBBS, MRCPsych, MD, PhD.

${ }^{1}$ Institute of Psychiatry, London, UK.

${ }^{2}$ Hospital del Mar, IAPS, Barcelona, Spain.

${ }^{3}$ Hospital de Sant Pau, Barcelona, Spain

${ }^{4}$ Li Ka Shink Faculty of Medicine, Honk Kong University, China

\section{ADDRESS FOR REPRINTS}

Elvira Bramon

Institute of Psychiatry, Division of Psychological Medicine - box 63, De Crespigny Park, London, SE5 8AF, United Kingdom.

Tel: 02078485036

Fax: 02077019044

E-mail: elvira.bramon@iop.kcl.ac.uk 


\section{INTRODUCTION}

Individuals with an 'At Risk Mental State' (ARMS) experience 'prodromal' symptoms and previous studies report that between 20 and $40 \%$ of them make a transition to psychosis within one or two years (Addington et al., 2007; Broome et al., 2005a; Klosterkotter et al., 2001; McGlashan et al., 2007; McGlashan et al., 2004; Morrison et al., 2002; Olsen and Rosenbaum, 2006; Schultze-Lutter et al., 2007; Yung et al., 2007; Yung et al., 2003; Yung et al., 2004). The basis of the vulnerability to psychosis in this group is unknown and, whilst evidence shows that psychological and pharmacological interventions improve outcomes (Bechdolf et al., 2005; McGorry et al., 2002; Miller et al., 2003; Phillips et al., 2005; Ruhrmann et al., 2005; Woods et al., 2003), treating high risk subjects remains controversial since most of them are not destined to develop the disease (Broome et al., 2005b; Cornblatt et al., 2001; Haroun et al., 2006). The identification of biological measures associated with a subsequent transition to psychosis would help to target early treatment to those who require it (Bender et al., 2007; Bramon et al., 2004a; Eastvold et al., 2007; Mason et al., 2004; Pantelis et al., 2003; Simon et al., 2007; van der Stelt and Belger, 2007).

Neurophysiology provides a non-invasive method to evaluate brain function related to cognitive and perceptual processes in vivo. The P300 wave reflects cortical activity during a form of continuous performance task in which subjects respond to target stimuli embedded at random in a sequence of standard stimuli. This event-related potential is more specifically known as the P3b in order to distinguish it from the P3a, a response to task-irrelevant novel infrequent stimuli not examined in this paper (Araki et al., 2006; Frodl-Bauch et al., 1999; Laurens et al., 2005; Mathalon et al., 2000; Salisbury et al., 2004; Salisbury et al., 2001; Sponheim et al., 2006). Another EEG marker investigated here, the N100 wave, reflects the early phase of attentive stimulus processing (Boutros et al., 2004; McCarley et al., 1991).

A meta-analysis of studies over the last decade indicates that the amplitude of the P300 (the P3b wave) is severely reduced and its peak is substantially delayed in patients with schizophrenia (Bramon 
et al., 2004b). Qualitatively similar, but less severe, deviances in amplitude and latency are also evident in the non-psychotic relatives of patients with schizophrenia (Blackwood et al., 1991; Bramon et al., 2005; Bramon et al., 2004b; Frangou et al., 1997). P300 deviances may thus constitute markers of a genetic predisposition to develop/transmit psychosis (Ahveninen et al., 2006; Braff et al., 2007; Bramon et al., 2006; Calkins et al., 2007; Cannon and Keller, 2006; Golimbet et al., 2006; Gottesman and Gould, 2003; Hall et al., 2006a; Hall et al., 2006b; Mulert et al., 2006; Price et al., 2006; Schulze et al., In press; Sumich et al., 2006; Sumich et al., 2007; Turetsky et al., 2007). Some, but not all, previous studies show N100 amplitude reductions in schizophrenic patients (Ahveninen et al., 2006; Brown et al., 2002; Frangou et al., 1997; Heinks-Maldonado et al., 2007; Javitt et al., 2000; Kogoj et al., 2005; O'Donnell et al., 2004; Pfefferbaum et al., 1984; Roth et al., 1981; Roth et al., 1980; Shelley et al., 1999; Sumich et al., 2006; Sumich et al., 2007; Winterer et al., 2001) but the N100 wave has not been examined in populations with high risk of developing psychosis.

Van der Stelt et al (van der Stelt et al., 2005) were the first to report P300 amplitude reductions in prodromal cases, which were of similar severity to those found in patients with recent onset as well as chronic schizophrenia. We set out to replicate this finding and to examine other EEG markers such as the N100 wave in an independent sample.

\section{METHODS AND MATERIALS}

Subjects were 35 people with an at risk mental state according to criteria established by Yung and colleagues, which include people with sub-clinical "attenuated" psychotic experiences, individuals with psychotic symptoms of insufficient duration to reach a diagnosis (brief limited intermittent psychotic symptoms known as BLIPS), and finally individuals with a schizotypal personality disorder or with a first-degree relative with psychosis who had a significant decline in function (Yung et al., 2005). These were compared against 57 healthy volunteers with no family or personal history of psychotic disorders. At risk subjects were recruited through the clinical service "Out-reach And Support In South London”(OASIS) (Broome et al., 2005a). Controls were recruited from the same geographical area by advertisements in the local press. Participants were excluded if they had 
neurological disorders, or head injury with loss of consciousness longer than ten minutes or a DSMIV diagnosis of alcohol or illegal substance dependence or abuse in the 12 months prior to assessment. Alcohol and other substance use, not reaching criteria for dependence or abuse, did not constitute exclusion criteria to ensure the sample was representative of our population. Of the thirty five cases at risk all but three were antipsychotic naïve and none of them were taking antipsychotics at the time of EEG testing. None of the controls were on any psychotropic medication at the time of EEG testing. All participants gave written informed consent to enter the study. This research was approved by the Ethical Committee at the Institute of Psychiatry.

Clinical assessments: All participants were interviewed to collect information on socio-demographic, physical and mental health data and the timing and nature of any symptoms. The instrument used to identify at risk cases was the Comprehensive Assessment of At-Risk Mental States (CAARMS) (Yung et al., 2005). The Family Interview for Genetic Studies (Nurnberger et al., 1994) was used to obtain/rule out any psychiatric diagnoses in the participant's first and second degree relatives. Transition to psychosis was defined using the threshold criteria in the CAARMS (Yung et al., 2005).

P300 paradigm: The P300 and N100 were obtained with a standard auditory oddball paradigm (Bramon et al., 2005). Stimuli were four hundred $80 \mathrm{~dB}$ tones, with a $2( \pm 0.2)$ seconds inter-stimulus interval presented through bilateral intra-aural earphones. $80 \%$ of the tones were 'non-targets' of 1000 $\mathrm{Hz}$ and $20 \%$ were 'targets' of $1500 \mathrm{~Hz}$ in a random sequence. Subjects were instructed to keep their eyes open and press a button in response to target tones only. EEG data were collected from 64 scalp sites according to the 10/20 International System (Jasper, 1958) and were grounded at Fpz using syntered electrodes in a cap. Bilateral mastoids served as reference and vertical and horizontal electrooculographs monitored eye movements. Data were continuously digitised at $1000 \mathrm{~Hz}$ with a 0.05 to $100 \mathrm{~Hz}$ band-pass filter ( $24 \mathrm{~dB} /$ octave roll-off). Impedances were kept below $5 \mathrm{KOhms}$. A Neuroscan linear regression procedure was employed to minimise ocular artifacts (Semlitsch et al., 1986). The continuous EEG recording was epoched (-100 to $700 \mathrm{~ms}$ ), baseline corrected using the pre-stimulus interval (-100 to $0 \mathrm{~ms}$ ), band-pass filtered 0.05 to $45 \mathrm{~Hz}$ and averaged for targets and non-targets 
separately (Bramon et al., 2005; Frangou et al., 1997). The P300 was defined as a positive waveform generated by the target tones and peaking between $280-500$ ms post-stimulus. The N100 was defined as the first negative wave peaking between 60 and $140 \mathrm{~ms}$. The N100 wave was analysed for both frequent and rare tones (Brown et al., 2002) and the statistical details are reported for the rare tones by default and for frequent tones wherever relevant as stated in the text. P300 and N100 peak amplitudes and latencies were measured using a computer algorithm, which made the process blind to group affiliation.

Statistical analysis: The socio-demographic characteristics and task performance between groups were compared using $\chi^{2}$ for categorical and t-test for continuous variables. The P300 and the N100 waves were compared between cases at risk and healthy controls using linear mixed models fitted with maximum likelihood methods. FZ, CZ and PZ measures were analysed and the correlations between these electrodes within each individual were accounted for by including random intercepts for participants. This is needed to maintain correct type-1 error rates (for similar two-level or threelevel nested models see (Bramon et al., 2006; Bramon et al., 2005). The P300 amplitude was the dependent variable and group (at risk or control), electrode (FZ, CZ, PZ), sex and age were the independent variables. We examined interactions of group by sex, group by age and group by electrode. Similar analyses were conducted with P300 latency, N100 amplitude and N100 latency as dependent variables. For the P300 wave only, an additional analysis tested the group differences comparing left and right temporal electrodes (T7 and T8 respectively) again adjusting by age and sex and relevant interactions. Boxplots were used to examine departures from normality and none were detected. All analyses were conducted in STATA 9.2 using the xtreg and xtlogit commands for regression analysis adjusting for clusters (electrode measures) in the data.

\section{RESULTS}

This sample included 35 cases with at risk mental states (ARMS) as defined by Yung and colleagues (Yung et al., 2005) as well as 57 healthy volunteers. As can be seen in table 1, the two participant 
groups were similar in demographics including age, sex, ethnicity and education. Subjects with at risk mental states were significantly more likely to report recreational drug use $(\mathrm{p}<0.001)$ and also smoked significantly more cigarettes per day $(\mathrm{p}<0.01)$. Of the at risk group, $66 \%$ suffered attenuated subthreshold psychotic symptoms, $11 \%$ had brief limited intermittent psychotic symptoms (BLIPS), another 3\% were included because of having a schizotypal personality or a family history of psychosis in addition to functional decline. Finally, $11 \%$ had both attenuated and BLIPS symptoms and $9 \%$ fulfilled both attenuated and trait and state criteria.

There were no significant differences between groups in terms of task accuracy or speed. Thus correct responses were $99.0 \% \pm 2.0 \%$ for controls and $98.9 \% \pm 1.9 \%$ for the at risk group. Reaction times for the button press were $0.48 \pm 0.21$ and $0.50 \pm 0.16$ seconds in controls and at risk people respectively.

Table 1 about here

Two at risk participants disengaged from the service shortly after inclusion and their clinical outcome is unknown. These drop outs belonged to the attenuated symptoms category and did not differ in socio-demographic characteristics from those followed up successfully. Of the remaining 33 participants, after an average follow up of 23.5 months (range 1.6 to 46.8 ; SD 13.5 months), seven subjects (21.2\%) developed a full-blown psychotic episode. Amongst the cases at risk the mean GAF score at the end of the follow up period was 71.1 (range 40 to 90; SD 14.2). Compared to the cases remaining at risk, the seven individuals making a transition to psychosis did not differ significantly in age, sex, ethnicity, education or in their P300 or N100 amplitudes and latencies.

Cross-sectional comparison between "At risk" cases and controls in event related potentials:

We found a significant effect of group on P300 amplitude, with lower amplitudes in cases at risk than in controls (Midline estimated difference $=-2.9$ microvolt; 95\% CI: -5.0 to -0.8 ; $\mathrm{p}<0.01$. Temporal channels Est. Dif. $=-1.6$ microvolt; $95 \% \mathrm{CI}:-3.1$ to $-1.0 ; \mathrm{p}=0.04)$. The two groups did not differ significantly in P300 latency, N100 amplitude and N100 latency (both frequent and rare tones were 
examined for N100).

\section{Topographic effects:}

The P300 amplitude was largest and its latency most delayed at parietal compared to frontal sites (Est. Dif. amplitude PZ-FZ= 7.1 microvolt; $95 \%$ CI: 6.2 to $8.1 ; \mathrm{p}<0.01$. Est. Dif. latency PZ-FZ=23.7 milliseconds; $95 \% \mathrm{CI}$ : 14.0 to $33.4 ; \mathrm{p}<0.01$ ). The P300 amplitude was larger at left temporal than right temporal electrodes in both cases and controls (T7-T8 Est. Dif. $=0.9$ microvolt; $95 \%$ CI: 0.03 to 1.8; $\mathrm{p}=0.04)$. The group by temporal region interaction was not significant suggesting no evidence of lateralisation in the P300 amplitude deficits observed in our at-risk cases. The P300 latency showed no differences between left and right temporal regions. Finally, the N100 amplitude was larger (in absolute value) and its latency greater at frontal than parietal electrodes (Est. Dif. amplitude PZ-FZ= 3.8 microvolt; $95 \% \mathrm{CI}: 3.4$ to 4.2 ; $\mathrm{p}<0.01$. Est. Dif. latency PZ-FZ $=-13.3$ milliseconds; $95 \% \mathrm{CI}:-17.1$ to $-9.5 ; \mathrm{p}<0.01)$.

\section{Demographic variations:}

There were no significant findings for the P300 wave except for ageing, which marginally increased P300 amplitudes (Est. Dif $=0.24$ microvolt; 95\%CI: 0.02 to 0.46; $\mathrm{p}=0.04$ ). As for the N100 amplitude, in this sample women had a significantly greater amplitude than men (Est. Dif. $=-1.2$ microvolt; 95\%CI: -2.2 to $-0.2 ; \mathrm{p}=0.02$ ). Men had delayed N100 latencies compared to women (Est. Dif. $=-8.1$ ms; $95 \% \mathrm{CI}$ : -13.7 to $-2.4 ; p<0.01)$. Ageing was associated with delayed N100 latency to the frequent tones (Est. Dif. $=0.6 \mathrm{~ms} ; 95 \% \mathrm{CI}: 0.1$ to $1.2 ; \mathrm{p}=0.02$ ); however, this effect did not reach statistical significance for the N100 to the rare tones. Given the size of our sample and its narrow age range these minor demographic differences need to be taken with caution. Finally, there were no significant interactions of group with age, sex and topography covariates for any of the waves examined. Figures 1 and 2 provide further details about group comparisons in P300 and N100 performance.

Figure 1 about here

Figure 2 about here 


\section{DISCUSSION}

Our hypothesis, that the P300 in subjects with an at-risk mental state (AMRS) would differ from that in healthy volunteers, was confirmed, with its amplitude significantly reduced in the ARMS group. From twin studies we know that P300 traits are reliable and heritable (Hall et al., 2006a; Hall et al., 2006b; Hall et al., 2004; van Beijsterveldt and van Baal, 2002). P300 amplitude reductions as well as latency delays constitute markers of vulnerability for psychosis, as they are evident in the unaffected relatives of patients (Blackwood et al., 1991; Bramon et al., 2005; Bramon et al., 2004b; Frangou et al., 1997; Pierson et al., 2000; Turetsky et al., 2000; Winterer et al., 2003) and they show a significant genetic correlation with schizophrenia and bipolar disorder (Hall et al., 2007a; Hall et al., 2007b).

As for the topography, the P300 amplitude deficits in the at-risk cases were consistently observed in midline as well as temporal sites (McCarley et al., 1991; McCarley et al., 2002; Morstyn et al., 1983). However, we found no evidence that these deficits were left-lateralized and this could be due to our paradigm involving a button press; which is thought to diminish the abnormal P300 asymmetry in schizophrenia (Ford et al., 1994; Pfefferbaum et al., 1989; Renoult et al., 2007; Salisbury et al., 2001).

While ageing and task difficulty are known to influence P300 performance, especially its latency (Mori et al., 2007; Polich, 1996); demographic confounders are unlikely to explain our findings and all analyses were adjusted for age and sex. Use of cannabis and other drugs is a known risk factor for psychosis (Arseneault et al., 2004) and since the at-risk group reported recreational drug consumption more often than the controls this could have contributed to our findings. However, additional analyses (available from the authors upon request) show that in this sample illicit drug use had no significant main effect on the P300 amplitude or any of the other paradigms examined and that there were no significant group by drug use interactions. Finally, since all but three of the ARMS subjects were naïve to antipsychotic medication, and no subject was on antipsychotics at the time of EEG testing, the reduction in P300 amplitude is unlikely to be confounded by pharmacological treatment (Laurent 
et al., 1999). Our findings are consistent with the data from two previous smaller studies of the P300 in the ARMS, both of which reported reductions in amplitude (Mathalon et al., 2004; van der Stelt et al., 2005).

The P300 wave is associated with a task that involves attentional processing and a degree of executive functioning. An abnormal P300 in the ARMS is thus consistent with data from neuropsychological studies of this group, which suggest that the ARMS is associated with impaired performance on tasks that engage attention (such as the CPT) and executive processes (Brewer et al., 2005; Cornblatt et al., 2004; Lencz et al., 2006; Pukrop et al., 2007; Woods et al., 2003). Our findings are also consistent with data from a functional imaging study of the P300 which indicated that subjects with an at-risk mental state showed less activation in the temporal cortex than controls but more than patients with schizophrenia (Morey et al., 2005). Interestingly, whilst the at-risk cases showed normal accuracy and reaction time in the P300 task at a behavioral level, their cortical physiology was impaired. Increasing task difficulty and using multi-modal techniques (Bender et al., 2007; Molina et al., 2007; Price et al., 2006; Sponheim et al., 2006) should increase our ability to detect subtle cognitive changes in the prodrome of psychosis.

Like Van der Stelt et al (van der Stelt et al., 2005) we failed to find latency deficits in the ARMS group. Because individuals at increased genetic risk of schizophrenia consistently show moderate latency delays (Bramon et al., 2005), we expected a similar finding in populations at clinical risk. However, both available studies may lack statistical power and thus P300 latency deficits can not be ruled out until larger samples can be examined. Furthermore, our paradigm as well as Van der Stelt's only allows us to examine the P3b wave (a response elicited by the target stimuli that require a response from the subject). More complex P300 experiments incorporating additional infrequent novel stimuli that generate the P3a response would be worth investigating in the prodrome (Araki et al., 2006; Frodl-Bauch et al., 1999; Laurens et al., 2005; Mathalon et al., 2000; Salisbury et al., 2004; Salisbury et al., 2001; Sponheim et al., 2006; Sumich et al., 2007). 
A limitation of this study is that we lacked a sample of patients with schizophrenia to compare with our at-risk and control groups. Similarly, since only seven of our cases at risk converted to psychosis we do not have sufficient statistical power to compare them against those who remained at risk after follow up. Meta-analyses show that, compared to controls, P300 amplitude deficits are moderatesevere in chronic patients with schizophrenia with a pooled standardised effect size calculated as Cohen's d of 0.85 (95\% CI: 0.65 to $1.05 ; \mathrm{p}<0.001)$ and of moderate severity in their unaffected relatives with a pooled standardised effect size of $0.61(95 \%$ CI: 0.30 to $0.91 ; p<0.001)$ (Bramon et al., 2005; Bramon et al., 2004b; Cohen, 1969). Pooled standardised effect sizes as calculated above allow a direct comparison of the strenght of effects (Cohen, 1969). In this present study the standardized difference between at-risk subjects and controls at centro-parietal sites (averaging $\mathrm{CZ}$ and PZ measures as in the meta-analysis) was 0.49 . These data suggest that the deficits found in cases at-risk due to prodromal symptoms are less severe than those reported for chronic patients but, since they fall within the confidence interval, are comparable to the deficits described in populations with genetic risk, such as the unaffected first degree relatives of patients. However, direct comparisons, ideally with first episode patients, and especially longitudinal studies are needed to confirm this finding.

As an abnormal P300 is thought to reflect increased genetic risk for schizophrenia, this is compatible with the view that the high risk of psychosis in the ARMS may have a genetic basis. While only a minority of subjects in most ultra-high risk samples, including our own, have a known family history of psychosis, subjects could still be carrying risk alleles of genes that predispose to psychosis. Indeed, the attenuated psychotic symptoms that are characteristic of at-risk mental state populations were also described in approximately $50 \%$ of young adults who had a first degree relative with schizophrenia; and those young relatives who had additional high levels of schizotypy had a risk of developing psychosis comparable to the ARMS group (Johnstone et al., 2005). Both the relatives of patients with schizophrenia and individuals with an ARMS show neuropsychological and volumetric MRI abnormalities that are qualitatively similar to those seen in schizophrenia but are quantitatively less severe (Brewer et al., 2005; Woods et al., 2003). To date no studies of genetic factors in the ARMS 
have been completed, but these are ongoing and may clarify the contribution of genes to the vulnerability to psychosis in this group (Bender et al., 2007).

Neither the amplitude nor the latency of the N100 wave was abnormal in our ARMS group. Amplitude reductions and latency delays of the N100 wave have been described in chronic schizophrenia (Frangou et al., 1997; Karoumi et al., 2000; O'Donnell et al., 2004; Wood et al., 2006), but have not been evident in the non-psychotic relatives of patients (Frangou et al., 1997; Karoumi et al., 2000). To our knowledge, this is the first examination of N100 performance in the at-risk mental state. The existing evidence, although more limited than that for P300, indicates that the N100 deficits are not markers of risk but rather a correlate of chronic psychotic symptoms (Brown et al., 2002; Javitt et al., 2000; Kogoj et al., 2005; O'Donnell et al., 2004; Roth et al., 1980; Shelley et al., 1999; Sumich et al., 2007).

As for clinical outcomes after an average of two years follow up, the rate of transition in our sample was lower than in early studies of the ARMS, but there is considerable variation across centres, reflecting different populations and ascertainment methods (Addington et al., 2007; Broome et al., 2005a; Klosterkotter et al., 2001; McGlashan et al., 2007; McGlashan et al., 2004; Olsen and Rosenbaum, 2006; Schultze-Lutter et al., 2007; Yung et al., 2007; Yung et al., 2003; Yung et al., 2004), and a rate of $21 \%$ is in line with that reported in recent work from comparable populations in the UK (Morrison et al., 2002).

In summary, our data and a previous smaller study (van der Stelt et al., 2005) both indicate that the atrisk mental state is associated with a significant reduction in the amplitude of the P300 wave, possibly reflecting an underlying genetic predisposition. A longitudinal analysis examining whether P300 and other biological markers at baseline can help to predict clinical outcomes would be granted; however, large samples or a meta-analysis will be required to achieve sufficient statistical power. 


\section{ACKNOWLEDGMENTS}

This study was supported by the following charities: The Wellcome Trust, The Schizophrenia Research Fund and the National Alliance for Research on Schizophrenia and Depression, The Psychiatry Research Trust and the British Medical Association. E. Bramon was supported by a fellowship from The Wellcome Trust, a NARSAD young investigator award and a post-doctoral fellowship from the UK's Department of Health. M. Shaikh is sponsored by the Psychiatry Research Trust. Our special thanks go to all the people who volunteered to take part in this research.

\section{FINANCIAL DISCLOSURES}

None of the co-authors has any conflict of interests to declare. 


\section{REFERENCES - CHECK FORMAT IS RIGHT}

Addington, J., Cadenhead, K.S., Cannon, T.D., Cornblatt, B., McGlashan, T.H., Perkins, D.O., Seidman, L.J., Tsuang, M., Walker, E.F., Woods, S.W., Heinssen, R., 2007. North American Prodrome Longitudinal Study: a collaborative multisite approach to prodromal schizophrenia research. Schizophr Bull 33, 665-672.

Ahveninen, J., Jaaskelainen, I.P., Osipova, D., Huttunen, M.O., Ilmoniemi, R.J., Kaprio, J., Lonnqvist, J., Manninen, M., Pakarinen, S., Therman, S., Naatanen, R., Cannon, T.D., 2006. Inherited auditory-cortical dysfunction in twin pairs discordant for schizophrenia. Biol Psychiatry 60, 612-620.

Araki, T., Kasai, K., Kirihara, K., Yamasue, H., Kato, N., Kudo, N., Nakagome, K., Iwanami, A., 2006. Auditory P300 latency prolongation with age in schizophrenia: gender and subcomponent effects. Schizophr Res 88, 217221.

Arseneault, L., Cannon, M., Witton, J., Murray, R.M., 2004. Causal association between cannabis and psychosis: examination of the evidence. British Journal of Psychiatry 184, 110-117.

Bechdolf, A., Veith, V., Schwarzer, D., Schormann, M., Stamm, E., Janssen, B., Berning, J., Wagner, M., Klosterkotter, J., 2005. Cognitive-behavioral therapy in the pre-psychotic phase: an exploratory study. Psychiatry Res 136, 251-255.

Bender, S., Weisbrod, M., Resch, F., 2007. Which perspectives can endophenotypes and biological markers offer in the early recognition of schizophrenia? J Neural Transm 114, 1199-1215.

Blackwood, D.H., St Clair, D.M., Muir, W.J., Duffy, J.C., 1991. Auditory P300 and Eye Tracking Dysfunction in Schizophrenic Pedigrees. Arch Gen Psychiatry 48, 899-909.

Boutros, N.N., Korzyukov, O., Jansen, B., Feingold, A., Bell, M., 2004. Sensory gating deficits during the midlatency phase of information processing in medicated schizophrenia patients. Psychiatry Res 126, 203-215.

Braff, D.L., Freedman, R., Schork, N.J., Gottesman, II, 2007. Deconstructing schizophrenia: an overview of the use of endophenotypes in order to understand a complex disorder. Schizophr Bull 33, 21-32.

Bramon, E., Croft, R.J., McDonald, C., Virdi, G.K., Gruzelier, J.G., Baldeweg, T., Sham, P.C., Frangou, S., Murray, R.M., 2004a. Mismatch negativity in schizophrenia: a family study. Schizophr Res 67, 1-10.

Bramon, E., Dempster, E., Frangou, S., McDonald, C., Schoenberg, P., MacCabe, J.H., Walshe, M., Sham, P., Collier, D., Murray, R.M., 2006. Is there an association between the COMT gene and P300 endophenotypes? European Psychiatry 21, 70-73.

Bramon, E., McDonald, C., Croft, R.J., Landau, S., Filbey, F., Gruzelier, J.H., Sham, P.C., Frangou, S., Murray, R.M., 2005. Is the P300 wave an endophenotype for schizophrenia? A meta-analysis and a family study. Neuroimage 27, 960-968.

Bramon, E., Rabe-Hesketh, S., Sham, P., Murray, R.M., Frangou, S., 2004b. Meta-analysis of the P300 and P50 waveforms in schizophrenia. Schizophr Res 70, 315-329.

Brewer, W.J., Francey, S.M., Wood, S.J., Jackson, H.J., Pantelis, C., Phillips, L.J., Yung, A.R., Anderson, V.A., McGorry, P.D., 2005. Memory impairments identified in people at ultra-high risk for psychosis who later develop first-episode psychosis. Am J Psychiatry 162, 71-78.

Broome, M.R., Woolley, J.B., Johns, L.C., Valmaggia, L.R., Tabraham, P., Gafoor, R., Bramon, E., McGuire, P.K., 2005a. Outreach and support in south London (OASIS): implementation of a clinical service for prodromal psychosis and the at risk mental state. European Psychiatry 20, 372-378.

Broome, M.R., Woolley, J.B., Tabraham, P., Johns, L.C., Bramon, E., Murray, G.K., Pariante, C., McGuire, P.K., Murray, R.M., 2005b. What causes the onset of psychosis? Schizophr Res 79, 23-34.

Brown, K.J., Gonsalvez, C.J., Harris, A.W., Williams, L.M., Gordon, E., 2002. Target and non-target ERP disturbances in first episode vs. chronic schizophrenia. Clin Neurophysiol 113, 1754-1763. 
Calkins, M.E., Dobie, D.J., Cadenhead, K.S., Olincy, A., Freedman, R., Green, M.F., Greenwood, T.A., Gur, R.E., Gur, R.C., Light, G.A., Mintz, J., Nuechterlein, K.H., Radant, A.D., Schork, N.J., Seidman, L.J., Siever, L.J., Silverman, J.M., Stone, W.S., Swerdlow, N.R., Tsuang, D.W., Tsuang, M.T., Turetsky, B.I., Braff, D.L., 2007. The Consortium on the Genetics of Endophenotypes in Schizophrenia: model recruitment, assessment, and endophenotyping methods for a multisite collaboration. Schizophr Bull 33, 33-48.

Cannon, T.D., Keller, M.C., 2006. Endophenotypes in the genetic analysis of mental disorders. Annual Review of Clinical Psychology 2, 267-290.

Cohen, J., 1969. Statistical Power Analysis for the Behavioral Sciences, first ed. Academic Press, Inc., New York.

Cornblatt, B., Lencz, T., Smith, C., Auther, A., Nakayama, E., McLaughlin, D., 2004. Neurocognitive risk factors identified in the New York recognition and prevention (RAP) program. 4th International Conference in Early Psychosis. Schizophrenia Research, p. 50.

Cornblatt, B.A., Lencz, T., Kane, J.M., 2001. Treatment of the schizophrenia prodrome: is it presently ethical? Schizophr Res 51, 31-38.

Eastvold, A.D., Heaton, R.K., Cadenhead, K.S., 2007. Neurocognitive deficits in the (putative) prodrome and first episode of psychosis. Schizophr Res 93, 266-277.

Ford, J.M., White, P.M., Csernansky, J.G., Faustman, W.O., Roth, W.T., Pfefferbaum, A., 1994. ERPs in schizophrenia: effects of antipsychotic medication. Biol Psychiatry 36, 153-170.

Frangou, S., Sharma, T., Alarcon, G., Sigmudsson, T., Takei, N., Binnie, C., Murray, R.M., 1997. The Maudsley family study .2. Endogenous event-related potentials in familial schizophrenia. Schizophr Res 23, 45-53.

Frodl-Bauch, T., Gallinat, J., Meisenzahl, E.M., Moller, H.J., Hegerl, U., 1999. P300 subcomponents reflect different aspects of psychopathology in schizophrenia. Biol Psychiatry 45, 116-126.

Golimbet, V., Gritsenko, I., Alfimova, M., Lebedeva, I., Lezheiko, T., Abramova, L., Kaleda, V., Ebstein, R., 2006. Association study of COMT gene Val158Met polymorphism with auditory P300 and performance on neurocognitive tests in patients with schizophrenia and their relatives. World J Biol Psychiatry 7, 238-245.

Gottesman, II, Gould, T.D., 2003. The endophenotype concept in psychiatry: Etymology and strategic intentions. American Journal of Psychiatry 160, 636-645.

Hall, M.-H., Rijsdijk, F., Picchioni, M., Schulze, K., Ettinger, U., Toulopoulou, T., Bramon, E., Murray, R.M., Sham, P., 2007a. Substantial Shared Genetic Influences on Schizophrenia and Event-Related Potentials. Am J Psychiatry 164, 804-812.

Hall, M.H., Rijsdijk, F., Kalidindi, S., Schulze, K., Kravariti, E., Kane, F., Sham, P., Bramon, E., Murray, R.M., 2007b. Genetic overlap between bipolar illness and event-related potentials. Psychol Med, 1-12.

Hall, M.H., Schulze, K., Bramon, E., Murray, R.M., Sham, P., Rijsdijk, F., 2006a. Genetic overlap between P300, P50, and duration mismatch negativity. Am J Med Genet B Neuropsychiatr Genet 141, 336-343.

Hall, M.H., Schulze, K., Rijsdijk, F., Picchioni, M., Ettinger, U., Bramon, E., Freedman, R., Murray, R.M., Sham, P., 2006b. Heritability and Reliability of P300, P50 and Duration Mismatch Negativity. Behav Genet 36, 845857.

Hall, M.H., Schulze, K., Sham, P., Picchioni, M., Ettinger, U., Rijsdijk, F., Bramon, E., Freedman, R., Murray, R.M., 2004. Test-retest reliability of ERP components of P300, P50 and duration mismatch negativity in monozygotic twins. Schizophr Res 67, 129-129.

Haroun, N., Dunn, L., Haroun, A., Cadenhead, K.S., 2006. Risk and protection in prodromal schizophrenia: ethical implications for clinical practice and future research. Schizophr Bull 32, 166-178.

Heinks-Maldonado, T.H., Mathalon, D.H., Houde, J.F., Gray, M., Faustman, W.O., Ford, J.M., 2007. Relationship of imprecise corollary discharge in schizophrenia to auditory hallucinations. Arch Gen Psychiatry 
64, 286-296.

Jasper, H., 1958. Report to the committee on methods of clinical examination in electroencephalography. Electroencephalography and Clinical Neurophysiology 10, 371-375.

Javitt, D.C., Jayachandra, M., Lindsley, R.W., Specht, C.M., Schroeder, C.E., 2000. Schizophrenia-like deficits in auditory P1 and N1 refractoriness induced by the psychomimetic agent phencyclidine (PCP). Clin Neurophysiol $111,833-836$.

Johnstone, E.C., Ebmeier, K.P., Miller, P., Owens, D.G., Lawrie, S.M., 2005. Predicting schizophrenia: findings from the Edinburgh High-Risk Study. Br J Psychiatry 186, 18-25.

Karoumi, B., Laurent, A., Rosenfeld, F., Rochet, T., Brunon, A., Dalery, J., d'Amato, T., Saoud, M., 2000. Alteration of event related potentials in siblings discordant for schizophrenia. Schizophr Res 41, 325-334.

Klosterkotter, J., Hellmich, M., Steinmeyer, E.M., Schultze-Lutter, F., 2001. Diagnosing schizophrenia in the initial prodromal phase. Arch Gen Psychiatry 58, 158-164.

Kogoj, A., Pirtosek, Z., Tomori, M., Vodusek, D.B., 2005. Event-related potentials elicited by distractors in an auditory oddball paradigm in schizophrenia. Psychiatry Res 137, 49-59.

Laurens, K.R., Kiehl, K.A., Ngan, E.T., Liddle, P.F., 2005. Attention orienting dysfunction during salient novel stimulus processing in schizophrenia. Schizophr Res 75, 159-171.

Laurent, A., Garcia_Larrea, L., d_Amato, T., Bosson, J.L., Saoud, M., Marie_Cardine, M., Maugiere, F., Dalery, J., 1999. Auditory event-related potentials and clinical scores in unmedicated schizophrenic patients. Psychiatry Research 86, 229-238.

Lencz, T., Smith, C.W., McLaughlin, D., Auther, A., Nakayama, E., Hovey, L., Cornblatt, B.A., 2006. Generalized and specific neurocognitive deficits in prodromal schizophrenia. Biol Psychiatry 59, 863-871.

Mason, O., Startup, M., Halpin, S., Schall, U., Conrad, A., Carr, V., 2004. Risk factors for transition to first episode psychosis among individuals with 'at-risk mental states'. Schizophr Res 71, 227-237.

Mathalon, D.H., Ford, J.M., Pfefferbaum, A., 2000. Trait and state aspects of P300 amplitude reduction in schizophrenia: a retrospective longitudinal study. Biol Psychiatry 47, 434-449.

Mathalon, D.H., Woods, S.W., Miller, T.J., Maher, S., Mochon, D., Oustinovskaya, M., McGlashan, T.H., 2004. Auditory and visual P300 amplitude reduction in patients with prodromal symptoms of schizophrenia. Biol Psychiatry 55, 30.

McCarley, R.W., Faux, S.F., Shenton, M.E., Nestor, P.G., Adams, J., 1991. Event-related potentials in schizophrenia: their biological and clinical correlates and a new model of schizophrenic pathophysiology. Schizophr Res 4, 209-231.

McCarley, R.W., Salisbury, D.F., Hirayasu, Y., Yurgelun-Todd, D.A., Tohen, M., Zarate, C., Kikinis, R., Jolesz, F.A., Shenton, M.E., 2002. Association between smaller left posterior superior temporal gyrus volume on magnetic resonance imaging and smaller left temporal P300 amplitude in first-episode schizophrenia. Arch Gen Psychiatry 59, 321-331.

McGlashan, T.H., Addington, J., Cannon, T., Heinimaa, M., McGorry, P., O'Brien, M., Penn, D., Perkins, D., Salokangas, R.K., Walsh, B., Woods, S.W., Yung, A., 2007. Recruitment and treatment practices for help-seeking "prodromal" patients. Schizophr Bull 33, 715-726.

McGlashan, T.H., Zipursky, R.B., Perkins, D.O., Addington, J., Woods, S.W., Miller, T.J., Lindborg, S.R., Trzaskoma, Q., Hawkins, K., Breier, A., 2004. Olanzapine for treatment of the schizophrenia prodrome: 2-year results of a randomized placebo-controlled study. Biol Psychiatry 55, 807.

McGorry, P.D., Yung, A.R., Phillips, L.J., Yuen, H.P., Francey, S., Cosgrave, E.M., Germano, D., Bravin, J., McDonald, T., Blair, A., Adlard, S., Jackson, H., 2002. Randomized controlled trial of interventions designed to 
reduce the risk of progression to first-episode psychosis in a clinical sample with subthreshold symptoms. Arch Gen Psychiatry 59, 921-928.

Miller, T.J., Zipursky, R.B., Perkins, D., Addington, J., Woods, S.W., Hawkins, K.A., Hoffman, R., Preda, A., Epstein, I., Addington, D., Lindborg, S., Marquez, E., Tohen, M., Breier, A., McGlashan, T.H., 2003. The PRIME North America randomized double-blind clinical trial of olanzapine versus placebo in patients at risk of being prodromally symptomatic for psychosis. II. Baseline characteristics of the "prodromal" sample. Schizophr Res 61, 19-30.

Molina, V., Reig, S., Sanz, J., Palomo, T., Benito, C., Sarramea, F., Pascau, J., Sanchez, J., Martin-Loeches, M., Munoz, F., Desco, M., 2007. Differential clinical, structural and P300 parameters in schizophrenia patients resistant to conventional neuroleptics. Prog Neuropsychopharmacol Biol Psychiatry.

Morey, R.A., Inan, S., Mitchell, T.V., Perkins, D.O., Lieberman, J.A., Belger, A., 2005. Imaging frontostriatal function in ultra-high-risk, early, and chronic schizophrenia during executive processing. Arch Gen Psychiatry 62 , 254-262.

Mori, Y., Kurosu, S., Hiroyama, Y., Niwa, S., 2007. Prolongation of P300 latency is associated with the duration of illness in male schizophrenia patients. Psychiatry Clin Neurosci 61, 471-478.

Morrison, A.P., Bentall, R.P., French, P., Walford, L., Kilcommons, A., Knight, A., Kreutz, M., Lewis, S.W., 2002. Randomised controlled trial of early detection and cognitive therapy for preventing transition to psychosis in high-risk individuals - Study design and interim analysis of transition rate and psychological risk factors. British Journal of Psychiatry 181, S78-S84.

Morstyn, R., Duffy, F.H., McCarley, R.W., 1983. Altered P300 topography in schizophrenia. Arch Gen Psychiatry 40, 729-734.

Mulert, C., Juckel, G., Giegling, I., Pogarell, O., Leicht, G., Karch, S., Mavrogiorgou, P., Moller, H.J., Hegerl, U., Rujescu, D., 2006. A Ser9Gly polymorphism in the dopamine D3 receptor gene (DRD3) and event-related P300 potentials. Neuropsychopharmacology 31, 1335-1344.

Nurnberger, J.I., Blehar, M.C., Kaufmann, C.A., York-Cooler, C., Simpson, S.G., Harkavy-Friedman, J., Severe, J.B., Malaspina, D., Reich, T., 1994. Diagnostic interview for genetic studies. Rationale, unique features, and training. NIMH Genetics Initiative. Arch Gen Psychiatry 51, 849-859.

O'Donnell, B.F., Vohs, J.L., Hetrick, W.P., Carroll, C.A., Shekhar, A., 2004. Auditory event-related potential abnormalities in bipolar disorder and schizophrenia. Int J Psychophysiol 53, 45-55.

Olsen, K.A., Rosenbaum, B., 2006. Prospective investigations of the prodromal state of schizophrenia: review of studies. Acta Psychiatr Scand 113, 247-272.

Pantelis, C., Velakoulis, D., McGorry, P.D., Wood, S.J., Suckling, J., Phillips, L.J., Yung, A.R., Bullmore, E.T., Brewer, W., Soulsby, B., Desmond, P., McGuire, P.K., 2003. Neuroanatomical abnormalities before and after onset of psychosis: a cross-sectional and longitudinal MRI comparison. Lancet 361, 281-288.

Pfefferbaum, A., Ford, J.M., White, P.M., Roth, W.T., 1989. P3 in schizophrenia is affected by stimulus modality, response requirements, medication status, and negative symptoms. Arch Gen Psychiatry 46, 1035-1044.

Pfefferbaum, A., Wenegrat, B., Ford, J., Roth, W., Kopell, B., 1984. Clinical applications of the P3 component of event-related potentials II. Dementia, depression and schizophrenia. Electroencephalography and Clinical Neurosphysiology 59, 104-124.

Phillips, L.J., McGorry, P.D., Yung, A.R., McGlashan, T.H., Cornblatt, B., Klosterkotter, J., 2005. Prepsychotic phase of schizophrenia and related disorders: recent progress and future opportunities. Br J Psychiatry Suppl 48, s33-44.

Pierson, A., Jouvent, R., Quintin, P., Perez-Diaz, F., Leboyer, M., 2000. Information processing deficits in relatives of manic depressive patients. Psychol Med 30, 545-555. 
Polich, J., 1996. Meta-analysis of P300 normative aging studies. Psychophysiology 33, 334-353.

Price, G.W., Michie, P.T., Johnston, J., Innes-Brown, H., Kent, A., Clissa, P., Jablensky, A.V., 2006. A multivariate electrophysiological endophenotype, from a unitary cohort, shows greater research utility than any single feature in the Western Australian family study of schizophrenia. Biol Psychiatry 60, 1-10.

Pukrop, Ruhrmann, Schultze, L., Bechdolf, Brockhaus, D., Klosterkötter, 2007. Neurocognitive indicators for a conversion to psychosis: Comparison of patients in a potentially initial prodromal state who did or did not convert to a psychosis. Schizophr Res 92, 116-125.

Renoult, L., Prevost, M., Brodeur, M., Lionnet, C., Joober, R., Malla, A., Debruille, J.B., 2007. P300 asymmetry and positive symptom severity: a study in the early stage of a first episode of psychosis. Schizophr Res 93, 366373.

Roth, W., Pfefferbaum, A., Kelly, A., Berger, P., Kopell, B., 1981. Auditory event related potentials in schizophrenia and depression. Psychiatry Research 4, 199-212.

Roth, W.T., Horvath, T.B., Pfefferbaum, A., Kopell, B.S., 1980. Event-related potentials in schizophrenics. Electroencephalogr Clin Neurophysiol 48, 127-139.

Ruhrmann, S., Schultze-Lutter, F., Maier, W., Klosterkotter, J., 2005. Pharmacological intervention in the initial prodromal phase of psychosis. Eur Psychiatry 20, 1-6.

Salisbury, D.F., Griggs, C.B., Shenton, M.E., McCarley, R.W., 2004. The NoGo P300 'anteriorization' effect and response inhibition. Clin Neurophysiol 115, 1550-1558.

Salisbury, D.F., Rutherford, B., Shenton, M.E., McCarley, R.W., 2001. Button-pressing affects P300 amplitude and scalp topography. Clin Neurophysiol 112, 1676-1684.

Schultze-Lutter, F., Ruhrmann, S., Hoyer, C., Klosterkotter, J., Leweke, F.M., 2007. The initial prodrome of schizophrenia: different duration, different underlying deficits? Compr Psychiatry 48, 479-488.

Schulze, K., Hall, M., Mc Donald, C., Marshall, N., Walshe, M., Murray, R., Bramon, E., In press. Auditory P300 in patients with bipolar disorder and their unaffected relatives. Bipolar Disorders.

Semlitsch, H.V., Anderer, P., Schuster, P., Presslich, O., 1986. A Solution for Reliable and Valid Reduction of Ocular Artifacts, Applied to the P300 Erp. Psychophysiology 23, 695-703.

Shelley, A.M., Silipo, G., Javitt, D.C., 1999. Diminished responsiveness of ERPs in schizophrenic subjects to changes in auditory stimulation parameters: implications for theories of cortical dysfunction. Schizophr Res 37, 65-79.

Simon, A.E., Cattapan-Ludewig, K., Zmilacher, S., Arbach, D., Gruber, K., Dvorsky, D.N., Roth, B., Isler, E., Zimmer, A., Umbricht, D., 2007. Cognitive functioning in the schizophrenia prodrome. Schizophr Bull 33, 761771.

Sponheim, S.R., McGuire, K.A., Stanwyck, J.J., 2006. Neural anomalies during sustained attention in first-degree biological relatives of schizophrenia patients. Biol Psychiatry 60, 242-252.

Sumich, A., Harris, A., Flynn, G., Whitford, T., Tunstall, N., Kumari, V., Brammer, M., Gordon, E., Williams, L.M., 2006. Event-related potential correlates of depression, insight and negative symptoms in males with recentonset psychosis. Clin Neurophysiol 117, 1715-1727.

Sumich, A., Kumari, V., Dodd, P., Ettinger, U., Hughes, C., Zachariah, E., Sharma, T., 2007. N100 and P300 amplitude to Go and No-Go variants of the auditory oddball in siblings discordant for schizophrenia. Schizophr Res.

Turetsky, B.I., Calkins, M.E., Light, G.A., Olincy, A., Radant, A.D., Swerdlow, N.R., 2007. Neurophysiological endophenotypes of schizophrenia: the viability of selected candidate measures. Schizophr Bull 33, 69-94. 
Turetsky, B.I., Cannon, T.D., Gur, R.E., 2000. P300 subcomponent abnormalities in schizophrenia: III. Deficits In unaffected siblings of schizophrenic probands. Biol Psychiatry 47, 380-390.

van Beijsterveldt, C.E., van Baal, G.C., 2002. Twin and family studies of the human electroencephalogram: a review and a meta-analysis. Biol Psychol 61, 111-138.

van der Stelt, O., Belger, A., 2007. Application of electroencephalography to the study of cognitive and brain functions in schizophrenia. Schizophr Bull 33, 955-970.

van der Stelt, O., Lieberman, J.A., Belger, A., 2005. Auditory P300 in high-risk, recent-onset and chronic schizophrenia. Schizophr Res 77, 309-320.

Winterer, G., Egan, M.F., Radler, T., Coppola, R., Weinberger, D.R., 2001. Event-related potentials and genetic risk for schizophrenia. Biol Psychiatry 50, 407-417.

Winterer, G., Egan, M.F., Raedler, T., Sanchez, C., Jones, D.W., Coppola, R., Weinberger, D.R., 2003. P300 and genetic risk for schizophrenia. Arch Gen Psychiatry 60, 1158-1167.

Wood, S.M., Potts, G.F., Hall, J.F., Ulanday, J.B., Netsiri, C., 2006. Event-related potentials to auditory and visual selective attention in schizophrenia. Int J Psychophysiol 60, 67-75.

Woods, S.W., Breier, A., Zipursky, R.B., Perkins, D.O., Addington, J., Miller, T.J., Hawkins, K.A., Marquez, E., Lindborg, S.R., Tohen, M., McGlashan, T.H., 2003. Randomized trial of olanzapine versus placebo in the symptomatic acute treatment of the schizophrenic prodrome. Biol Psychiatry 54, 453-464.

Yung, A.R., McGorry, P.D., Francey, S.M., Nelson, B., Baker, K., Phillips, L.J., Berger, G., Amminger, G.P., 2007. PACE: a specialised service for young people at risk of psychotic disorders. Med J Aust 187, S43-46.

Yung, A.R., Phillips, L.J., Yuen, H.P., Francey, S.M., McFarlane, C.A., Hallgren, M., McGorry, P.D., 2003. Psychosis prediction: 12-month follow up of a high-risk ("prodromal") group. Schizophr Res 60, 21-32.

Yung, A.R., Phillips, L.J., Yuen, H.P., McGorry, P.D., 2004. Risk factors for psychosis in an ultra high-risk group: psychopathology and clinical features. Schizophr Res 67, 131-142.

Yung, A.R., Yuen, H.P., McGorry, P.D., Phillips, L.J., Kelly, D., Dell'Olio, M., Francey, S.M., Cosgrave, E.M., Killackey, E., Stanford, C., Godfrey, K., Buckby, J., 2005. Mapping the onset of psychosis: the Comprehensive Assessment of At-Risk Mental States. Aust N Z J Psychiatry 39, 964-971.

\section{Table 1: Demographics of the sample with at-risk mental states (ARMS) and controls.}

ARMS: At-risk mental state. The two groups are well matched for the main demographic potential confounders.

SD: standard deviation.

Figure 1: P300 and N100 amplitude and latency comparisons between at risk cases and controls

Bar chart providing P300 and N100 amplitude / latency (means \pm 1 S.D) by electrode and group. 
P300 amplitude: Coef. $=-3.4$ microvolt; $95 \% \mathrm{CI}:-5.7$ to $-1.1 ; \mathrm{p}<0.01$.

P300 latency: Coef. $=1.9$ microvolt; $95 \%$ CI: -15.8 to $-19.6 ; \mathrm{p}=0.83$.

N100 amplitude: Coef. $=-0.1$ microvolt; $95 \% \mathrm{CI}:-1.3$ to $1.0 ; \mathrm{p}=0.83$.

N100 latency: Coef. $=-2.1$ microvolt; $95 \%$ CI: -7.5 to $3.4 ; \mathrm{p}=0.46$.

Figure 2: Group average $\mathrm{P300}$ and $\mathrm{N100}$ waves for 35 cases with at risk mental states and for 57 controls

Group averages of P300 and N100 at sites FZ, CZ and PZ. No group differences observed in P300 latency or in the amplitude and latency of the N100. A significant reduction in P300 amplitude was found in the prodromal group. 


\begin{tabular}{|c|c|c|c|}
\hline \multirow[b]{2}{*}{ Demographic variables } & ARMS & Controls & \multirow{3}{*}{ Group comparisons } \\
\hline & \multirow[b]{2}{*}{$\mathbf{N}=\mathbf{3 5}$} & \multirow[b]{2}{*}{$\mathbf{N}=57$} & \\
\hline & & & \\
\hline \multirow[t]{2}{*}{ Sex } & $60 \%$ & $42 \%$ & $\mathrm{X}^{2}(1)=2.78 ; \mathrm{P}=0.13$ \\
\hline & $65.7 \%$ & $73.7 \%$ & \\
\hline \multirow[t]{2}{*}{ Ethnicity } & $28.6 \%$ & $17.6 \%$ & \multirow[t]{2}{*}{$\mathrm{X}^{2}(1)=1.674 ; \mathrm{P}=0.43$} \\
\hline & $5.7 \%$ & $8.8 \%$ & \\
\hline \multirow[t]{2}{*}{ Years \pm SD } & $24.57 \pm 4.6$ & $24.53 \pm 4.5$ & \multirow{3}{*}{ T-test; $\mathrm{P}=0.96$} \\
\hline & & & \\
\hline range & $16-35$ & $19-35$ & \\
\hline \multicolumn{3}{|l|}{ Education } & \\
\hline (age completed studies) & $19.37 \pm 3.2$ & $20.60 \pm 3.7$ & T-test; $\mathrm{P}=0.10$ \\
\hline Regular drug use \% & $31.4 \%$ & $1.8 \%$ & $\mathrm{X}(1) ; \mathrm{P}<0.001$ \\
\hline Number of cigarettes/day \pm sd & $6.09 \pm 7.2$ & $1.55 \pm 4.1$ & T-test; $\mathrm{P}<0.01$ \\
\hline \multirow[t]{2}{*}{ P300 performance } & & & \\
\hline & $98.9 \pm 1.9 \%$ & $99.0 \pm 2.0 \%$ & T-test; $\mathrm{P}=0.62$ \\
\hline$\%$ correct responses & & & \\
\hline
\end{tabular}




\section{Figure 1}

Click here to download 5. Figure: Figure1_final.pdf
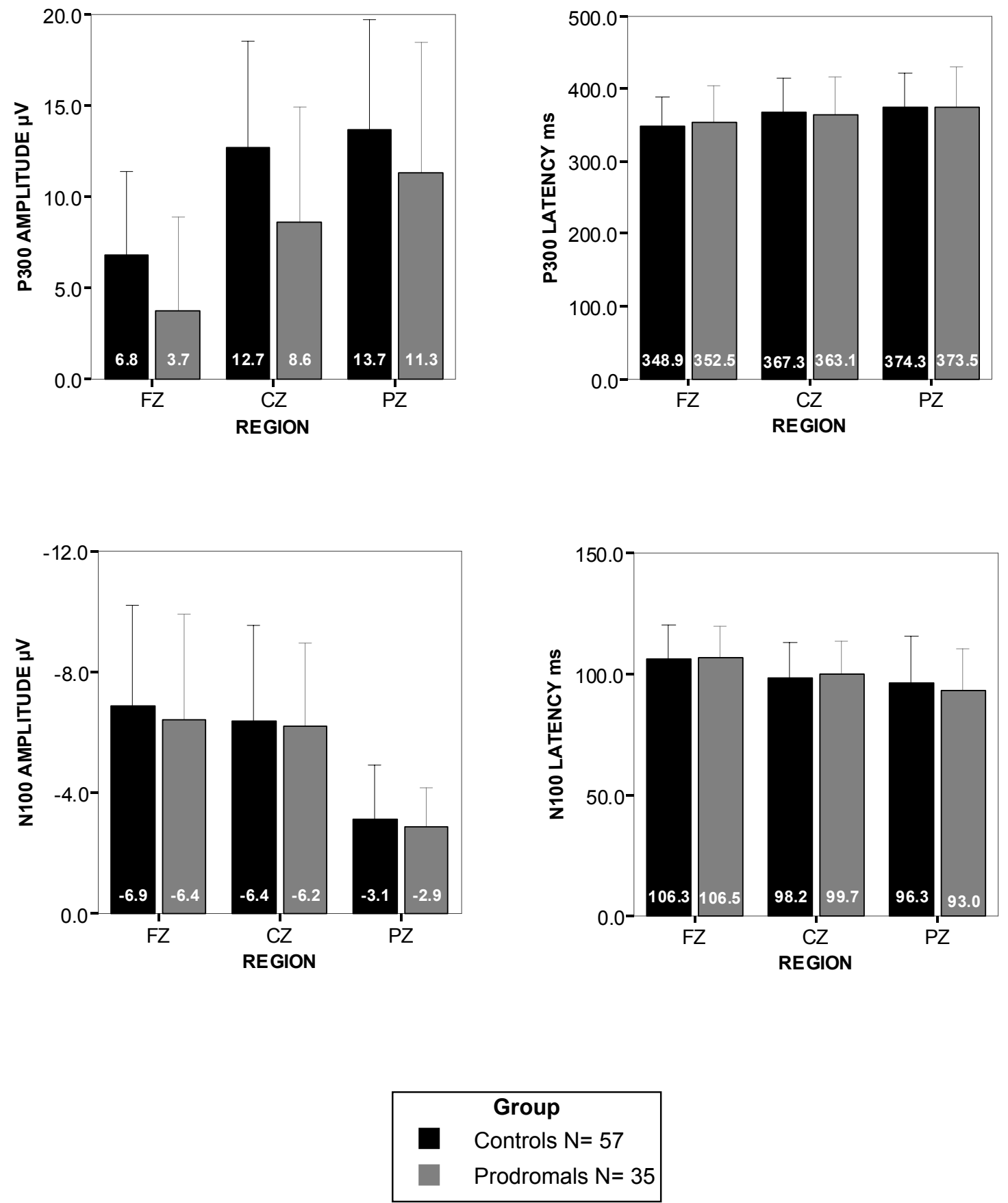


\section{Figure 2}

Click here to download 5. Figure: Figure2_final.pdf

FZ

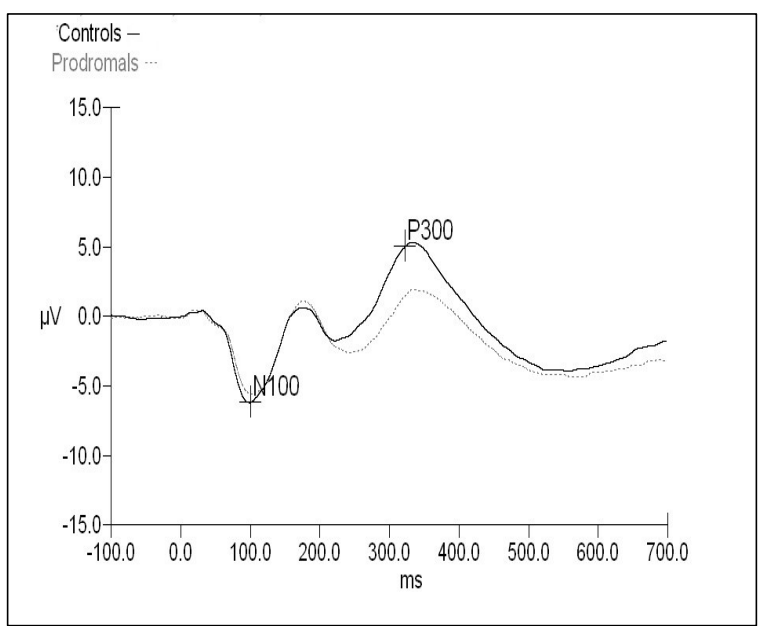

CZ

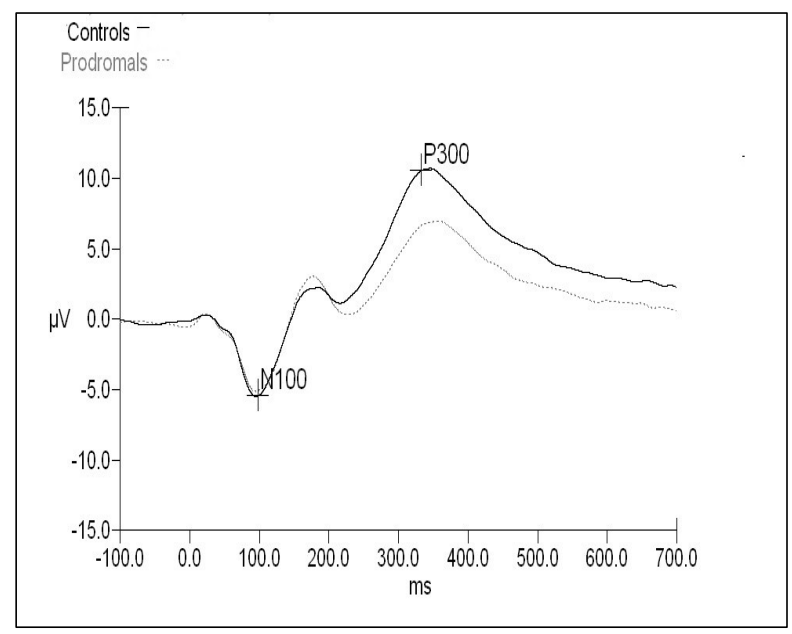

PZ

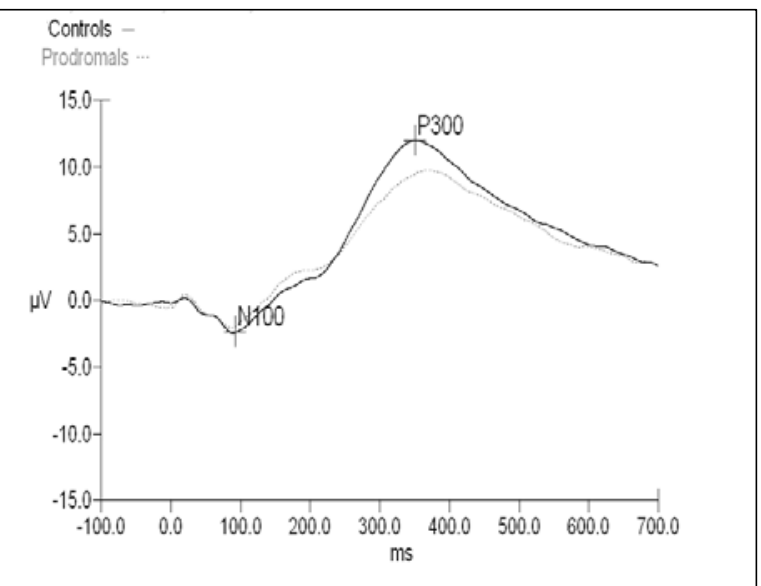

